\title{
CONDROSSARCOMA DE RAMO PÚBICO SUPERIOR SIMULANDO HÉRNIA INGUINAL
}

\section{CHONDROSARCOMA OF THE SUPERIOR PUBIC RAMUS SIMULATING AN INGUINAL HERNIA}

\author{
Fabio Terabe $^{1}$; Benedito Mauro Rossi, TCBC-SP²; Ademar Lopes, TCBC-SP ${ }^{3}$
}

\section{INTRODUÇÃO}

Os tumores primários da bacia são relativamente raros, representando cerca de $5 \%$ dos tumores ósseos primários $^{1}$. Considerando apenas os condrossarcomas, $25 \%$ dos casos estão localizados na bacia ${ }^{2}$. Tendo em vista a sua incidência, relatamos um caso para enfatizar a importância do correto diagnóstico destes tumores.

\section{RELATO DO CASO}

Paciente do sexo feminino, 27 anos, notou um abaulamento na região inguinal direita, indolor, de crescimento progressivo há alguns meses. Procurou serviço médico onde foi realizado diagnóstico de hérnia inguinal direita. Foram solicitados exames pré-operatórios de rotina e a paciente foi submetida à inguinotomia para realização de herniorrafia inguinal. Porém, foi encontrada uma tumoração fixa, endurecida, que foi curetada. $\mathrm{O}$ exame anatomopatológico demonstrou tratarse de um condrossarcoma de baixo grau.

Ao exame inicial, em nosso Serviço, encontrava-se em bom estado geral, sem particularidades no exame físico, exceto por abaulamento subcicatricial da região inguinal direita. A radiografia simples da bacia demonstrava tumor calcificado na região do ramo púbico superior direito (Figura 1a), confirmado pela tomografia e pela ressonância magnética (Figura 1b), medindo 90 x $50 \mathrm{~mm}$ nos maiores diâmetros. Não havia invasão do feixe vásculo-nervoso ilíaco externo direito. As tomografias de tórax e abdômen superior e a cintilografia óssea estavam normais.

A paciente foi submetida à ressecção ampla da lesão incluindo o ramo púbico superior, tendo sido possível preservar o acetábulo e o ramo púbico inferior (vide defeito ósseo residual na Figura 2). A parede da região ínguino-crural foi reconstruída com tela de polipropileno fixada no pubis, segmento remanescente do ísquio e fáscia lateral da coxa. O exame anatomopatológico demonstrou condrossarcoma grau II com infiltração focal de partes moles e margens de ressecção livres. A paciente teve evolução pós-operatória satisfatória e encontra-se em bom estado geral, deambulando sem dificuldades.

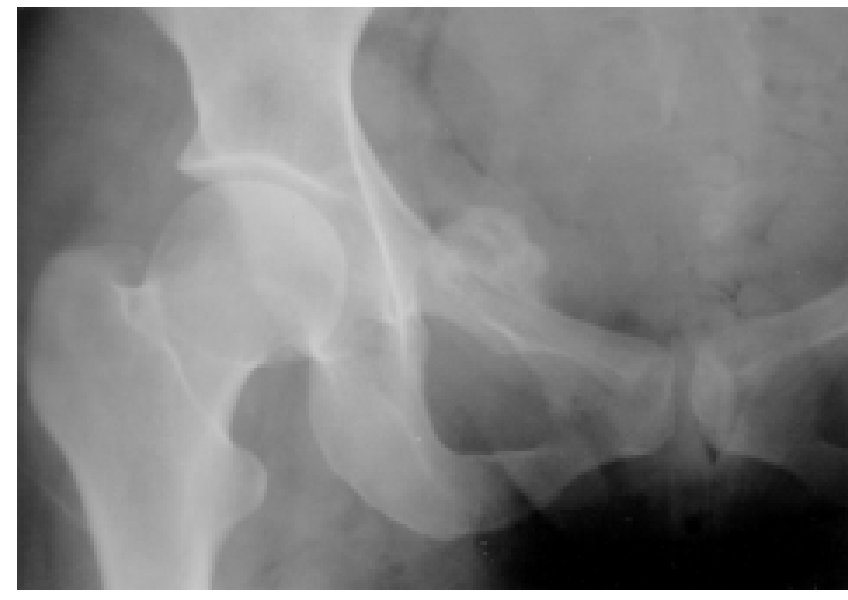

Figura 1a - Radiografia simples da bacia demonstrando a lesão calcificada.

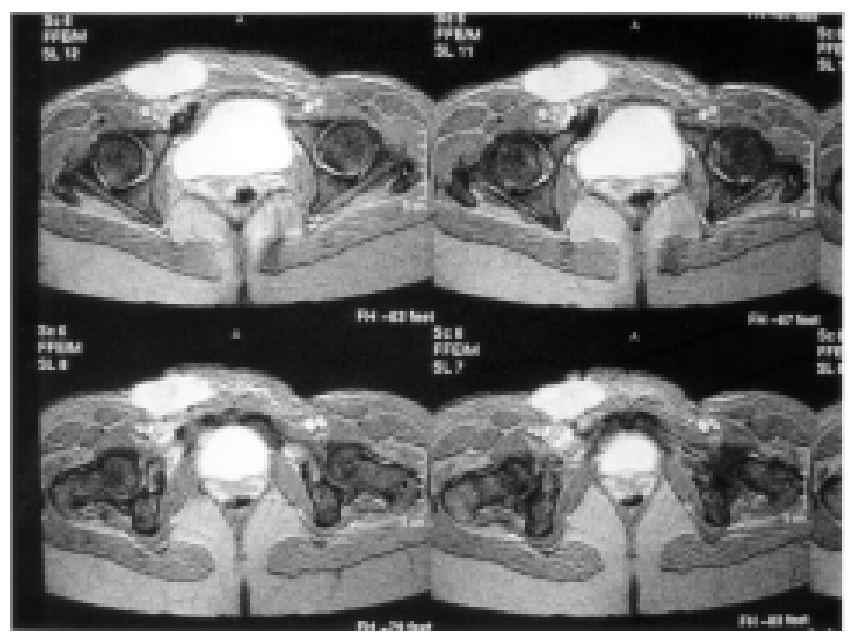

Figura $1 \boldsymbol{b}$ - Ressonância magnética da região demonstrando acometimento de partes moles.

\section{DISCUSSÃO}

O condrossarcoma é o segundo tumor ósseo mais freqüente e acomete principalmente a bacia, o fêmur proximal e a cintura escapular ${ }^{3}$. Na pelve pode apresentar-se como um tumor de crescimento indolente, inicialmente indolor. Assim,

1. Residente de Cirurgia Oncológica do Hospital do Câncer

2. Mestre e Doutor em oncologia

3. Chefe do Departamento de Cirurgia Pélvica do Hospital do Câncer; Livre Docente pela Disciplina de Oncologia da Universidade de São Paulo

Recebido em 18/08/2004

Aceito para publicação em 25/01/2005

Trabalho realizado no Departamento de Cirurgia Pélvica do Hospital do Câncer - Fundação Antônio Prudente, São Paulo. 


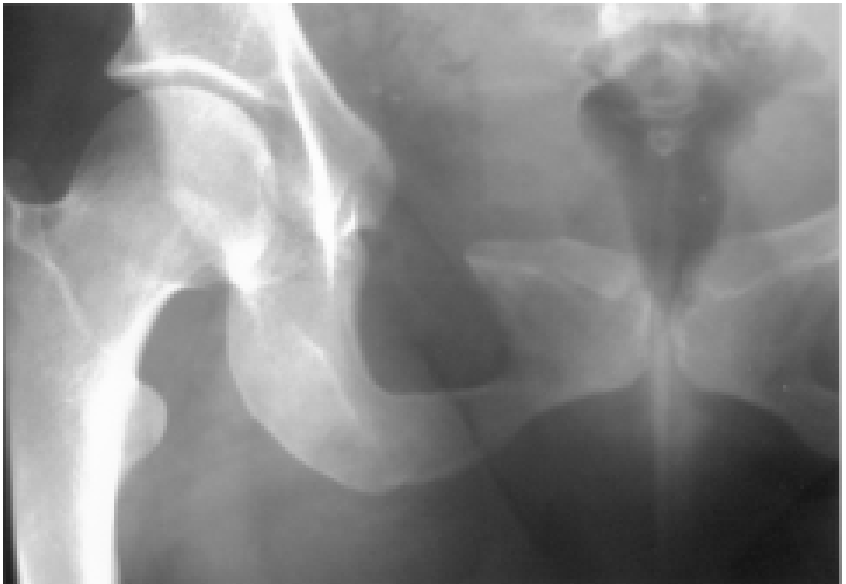

Figura 2 - Radiografia simples da bacia demonstrando o defeito ósseo.

o tamanho do tumor na época do diagnóstico é relativamente maior em relação aos sarcomas de extremidades, atingindo cerca de $12 \mathrm{~cm}^{2,4,5}$.

Na região inguinal os sarcomas são afecções pouco freqüentes, havendo a necessidade de descartar outros diagnósticos mais comuns, como as hérnias, adenopatias e lipomas. A investigação deve sempre incluir uma radiografia simples da bacia e exames mais detalhados, como a tomografia computadorizada ou ressonância magnética. Em virtude de sua raridade, há retardo no diagnóstico, embora não pareça existir associação do tempo de sintomas com o estádio ou a sobrevida. Especificamente em consideração ao diagnóstico equivocado de hérnia inguinal, demonstrou-se não ter havido diferença de sobrevida em 14 pacientes (16\% da amostra de 88 indivíduos portadores de sarcomas de região inguinal) que foram inicialmente submetidos à inguinotomia para herniorrafia e depois tratados adequadamente.

O tratamento consiste na ressecção cirúrgica com margens amplas, visto que a grande maioria dos casos não responde a outras modalidades de terapia (quimioterapia ou radioterapia). A sobrevida global em cinco anos varia entre $55 \%$ e $72 \%{ }^{2,4}$, embora séries mais antigas relatem taxas entre $25 \%$ e $54 \%{ }^{2}$.

O principal fator prognóstico para recorrência local é a realização de operação sem margens adequadas ${ }^{2,4,4}$. Outros fatores prognósticos são o grau histológico, a invasão neurovascular a localização no púbis e o tratamento inicial fora de um centro especializado ${ }^{2,5}$. Devemos ressaltar a importância da obtenção de margens oncologicamente livres, caso contrário os índices de recidiva local podem aumentar em até 3,3 vezes $^{5}$, com sobrevida livre de recidiva local em cinco anos de $27 \%-60 \%$ contra $82 \%{ }^{4}$. As taxas de recidiva local não são significativamente diferentes entre pacientes submetidos a ressecções conservadoras de membros e aqueles submetidos a procedimentos mutiladores ${ }^{4,5}$.

Com relação à ocorrência de metástases, o fator prognóstico mais importante é o grau histológico ${ }^{2,5}$. Assim, os pacientes portadores de condrossarcomas de alto grau possuem maior probabilidade de evoluir com doença metastática e óbito. Estes indivíduos devem ser incluídos em protocolos de quimioterapia neoadjuvante ou adjuvante.

Devemos relembrar a importância do diagnóstico diferencial com sarcomas em lesões da região pélvica com o objetivo de: (a) evitar manipulações mal conduzidas que possam ocasionar a disseminação local de células neoplásicas e piora das taxas de recidiva local e sobrevida; e (b) tentar realizar diagnósticos precoces que permitam o tratamento cirúrgico adequado de maneira conservadora.

\begin{abstract}
Primary pelvic tumors are relatively rare, representing no more than 5\% of primary bone tumors. We presented a case of a chondrosarcoma of the superior pubic ramus initially managed as an inguinal hernia and then operated under oncological principles. Special attention is attributed to the importance for the correct diagnosis and surgical treatment given the low efficacy of adjuvant treatments for this type of neoplasia (Rev. Col. Bras. Cir. 2005; 32(5): 353-354).
\end{abstract}

Key words : Chondrosarcoma; Sarcoma; Pubic bone

\section{REFERÊNCIAS}

1. Malawer MM. Hemipelvectomias internas parciais. In: Malawer MM, Sugarbaker PH, Lopes A, editores. Atlas de cirurgia para sarcomas ósseos e de partes moles. $1^{\mathrm{a}}$ ed. São Paulo: Lemar; 2003. p. 279-93.

2. Bergh P, Gunterberg B, Meis-Kindblom JM, et al. Prognostic factors and outcome of pelvic, sacral and spinal chondrosarcomas: a center-based study of 69 cases. Cancer. 2001; 91(7):1201-12.

3. Malawer MM, Link MP, Donaldson SS. Sarcomas of bone. In: DeVita VT, Hellman S, Rosenberg SA, editors. Cancer - principles and practice of oncology. $6^{\text {th }}$ ed. Philadelphia: Lippincott Williams \& Wilkins; 2001. p. 1891-935.

4. Kawai A, Healey JH, Boland PJ, et al. Prognostic factors for patients with sarcomas of the pelvic bones. Cancer. 1998; 82(5):851-9.
5. Sheth DS, Yasko AW, Johnson ME, et al. Chondrosarcoma of the pelvis. Prognostic factors for 67 patients treated with definitive surgery. Cancer. 1996; 78(4): 745-50.

Endereço para correspondência:

Ademar Lopes

Hospital do Câncer A. C. Camargo

Departamento de Cirurgia Pélvica

R. Prof. Antônio Prudente, 211

Liberdade

01509-900 - São Paulo - SP, Brasil 